\title{
Modifying the Charge State Distribution of Proteins in Electrospray Ionization Mass Spectrometry by Chemical Derivatization
}

\author{
Casey J. Krusemark, ${ }^{\text {a }}$ Brian L. Frey, ${ }^{\mathrm{b}}$ Peter J. Belshaw, ${ }^{\mathrm{a}, \mathrm{b}}$ and \\ Lloyd M. Smith ${ }^{\mathrm{b}}$ \\ a Department of Biochemistry, University of Wisconsin-Madison, Madison, Wisconsin, USA \\ ${ }^{b}$ Department of Chemistry, University of Wisconsin-Madison, Madison, Wisconsin, USA
}

\begin{abstract}
Electrospray ionization (ESI) of denatured proteins produces a broad distribution of multiplycharged ions leading to multiple peaks in the mass spectrum. We investigated changes in the positive-mode ESI charge state distribution produced by several chemical modifications of denatured proteins. Capping carboxylic acid groups with neutral functional groups yields little change in charge state distribution compared with unmodified proteins. The results indicate that carboxyl groups do not play a significant role in the positive charging of denatured proteins in ESI. The modification of proteins with additional basic sites or fixed positive charges generates substantially higher charge states, providing evidence that the number of ionizable sites, rather than molecular size and shape, determines ESI charging for denatured proteins. Fixed charge modification also significantly reduces the number of protons acquired by a protein, in that the charge state envelope is not increased by the full number of fixed charges appended. This result demonstrates that Coulombic repulsion between positive charges plays a significant role in determining charge state distribution by affecting the gas-phase basicity of ionizable sites. Addition of fixed-charge moieties to a protein is a useful approach for shifting protein charge state distributions to higher charge states, and with further work, it may help limit the distribution of protein ions to fewer charge states. (J Am Soc Mass Spectrom 2009, 20, 1617-1625) (c) 2009 American Society for Mass Spectrometry
\end{abstract}

$\mathrm{T}$ The development of electrospray ionization (ESI) has been critical for the analysis of intact proteins by mass spectrometry (MS). Electrospray ionization of proteins creates a distribution of ions in high charge states. This multiple charging allows for very accurate measurement of even large molecular weight proteins with most types of mass spectrometers, which has made ESI the ionization method of choice for MS characterization of intact proteins. In many cases, however, the charging of proteins by ESI is less than optimal. Having control over protein charge states could have several advantages. It would be beneficial to concentrate signal observed from proteins into fewer charge states, both to simplify spectra and to improve signal-to-noise ratios. Such improvements could dramatically improve the analysis of protein mixtures, which can be complicated by spectral overlap. Also, it would be advantageous for protein ions to exist in a few high charge states, as opposed to a few low charge states, because most mass spectrometers are better suited to these lower $\mathrm{m} / \mathrm{z}$ ions. Furthermore, highly

Address reprint requests to Dr. L. M. Smith, Department of Chemistry, University of Wisconsin, 1101 University Ave., Madison, WI 53706-1396, USA. E-mail: Smith@Chem.WISC.EDU charged protein ions tend to acquire fewer adducts [1, 2], and fragment more efficiently than protein ions of low charge [3-5].

Several factors affect the distribution of the charge states in a protein ESI mass spectrum including electrospray solvent, instrumental factors, and the protein's primary structure and conformation [6, 7]. The contributions of protein functional groups, particularly acidic and basic groups, to the charge state distribution are not fully understood. Most cases of positive-mode ESI of peptides and proteins show that charges are localized primarily at highly basic groups (Lys, Arg, His, Nterminus) [7, 8]; however, the number of basic groups alone does not fully explain the charging behavior. In peptides, the dominant effect governing charge state distribution appears to be charge-charge repulsion between protonated basic sites. Polyarginine peptides, for instance, take on significantly fewer charges than the number of basic groups [9]. While some studies with peptides have shown that carboxyl groups do not decrease charging in positive-mode ESI [7], recent work by Samalikova and Grandori has provided some evidence that carboxyl groups can negatively affect the positive charging of a peptide [10]. In their work, a significant increase in charging occurred for the peptide 
angiotensin when an aspartic acid residue was replaced with an asparagine. This result raises the question as to whether carboxyl groups exist in their deprotonated form in gas-phase peptide/protein cations.

Deprotonated carboxyl groups would not be expected on positively-charged peptide or protein ions based upon intrinsic gas-phase basicity considerations; nonetheless, some evidence for such gas-phase salt bridges does exist. The intrinsic gas-phase basicity (GB) of a carboxylate anion (334.7 kcal/mol for glycine) [11] is significantly higher than that of the guanidium group of Arg in a protein (251 kcal/mol) [12], which indicates that proton transfer would occur from a protonated basic group to the deprotonated carboxyl unless there was substantial charge stabilization $(\sim 84 \mathrm{kcal} / \mathrm{mol})$. Modeling and measurements by reactions with volatile bases have shown gas-phase basicities of basic groups on proteins can be lowered substantially by Coulombic interactions to give apparent GB's that are up to $\sim 50$ $\mathrm{kcal} / \mathrm{mol}$ lower than the intrinsic values $[13,14]$. Some direct evidence has been obtained for gas-phase salt bridging interactions in the arginine dimer and the peptide bradykinin. Both examples involve zwitterions consisting of a negative ion between two positively charged arginines through a $(+) \ldots(-) \ldots(+)$ motif $[15,16]$. For the bradykinin $[\mathrm{M}+\mathrm{H}]^{+}$ion, a combination of molecular mechanics and density functional theory calculations found the salt-bridge structure is $\sim 10 \mathrm{kcal} / \mathrm{mol}$ lower in energy than the structures having a single protonated arginine [17]. Furthermore, a recent study with several peptides has indicated the presence of gas-phase salt bridges as detected by losses of $\mathrm{CO}_{2}(44 \mathrm{Da})$ via ultraviolet photodissociation [8]. These studies suggest that deprotonated carboxyls, as part of salt bridges, can exist in some cases of peptides and amino acids. Protein ions would seem even more likely to exhibit this behavior due to secondary and tertiary structure increasing the capability for charge stabilization.

Investigations of native folded proteins have provided evidence that both basic groups and carboxyl groups in the protein can influence the charge state distribution during positive-mode ESI-MS [10, 14, 18, 19]. Folded protein spectra have shown a direct correlation between the location of acidic and basic groups within the crystal structure and the maximum charge state observed [19]. It was found that the maximum positive charge state correlated to the number of "free" basic groups on the protein surface, which were basic residues not involved in hydrogen bonding or saltbridging interactions with carboxyl groups. These salt bridges may remain intact $[14,19]$ or a proton transfer may occur upon desolvation [20].

Alternatively, protein size and shape have been considered as major determinants of the charge state distribution of folded proteins [10, 14, 18, 19, 21-25]. The charge residue model (CRM) originally presented by Fernandez de la Mora correlates well with experimental data for folded (globular) proteins, and it states that the maximum charge state corresponds to the Rayleigh limit of charges on a droplet of that size [20, $23,26]$. Recent work by Hogan and coworkers shows a strong correlation between the square of the ion mobility diameter of a protein and the mean ESI charge state, which is well below the Rayleigh limit [24, 25]. These correlations seem to hold regardless of the exact numbers of acidic or basic functional groups present, although that may be aided by proteins typically having sufficient basic residues to accommodate that number of charges [27]. These models are additionally supported by chemically modified, peracetylated folded proteins, which show little change in charge state distribution compared with their unmodified forms [28].

Proteins electrosprayed from denaturing conditions acquire more charges than their folded counterparts and have a wider charge state distribution. Williams and coworkers developed a model for determining the maximum charge state of protein ions generated in the ESI process [13]. Their model employs calculations of apparent gas-phase basicity of a protein, taking into account the point-charge Coulomb interactions (i.e., charge-charge repulsion), and modeling the protein in an extended chain form. The maximum charge state for a protein is predicted by calculating the charge state with a gas-phase basicity closest to that of the electrospray solvent. The predictions agree remarkably well with the maximum charge state observed by ESI-MS for several denatured proteins. However, the majority of protein ions exist in charge states lower than the maximum observed state, and the model does not attempt to explain the origin of these ions. A plausible explanation for these ions is that they represent various partiallyfolded proteins. Ion mobility spectrometry and H/D exchange measurements present evidence for several stable structural conformations in protein ion populations [29-31]. Carboxyl groups could stabilize such conformations either through salt-bridges or hydrogen bonds, and thereby impact the charge state distribution of denatured proteins. In this role, carboxyls may contribute to the observed less than maximal charging in positive mode ESI-MS.

Several methods have been developed that allow for some control over protein charge states. The majority of these methods lower the charge states of ions. The addition of compounds of high gas-phase basicity to electrospray solutions has been used to shift the charge state distribution of protein ions to lower charge states through proton transfer [32-34]. Also ion/molecule [35, 36] and ion/ion [37, 38] reactions employing either neutral bases or anions, respectively, have been used in the gas phase to reduce the charge of proteins. While high charge states are generally desirable, little has been accomplished to increase the charging of proteins. Williams and coworkers have demonstrated some increases in charging ("supercharging") over conventional conditions by the addition of solvents, such as glycerol and $m$-nitrobenzyl alcohol, to produce ESI droplets of higher surface tension [6, 39]. Additional 


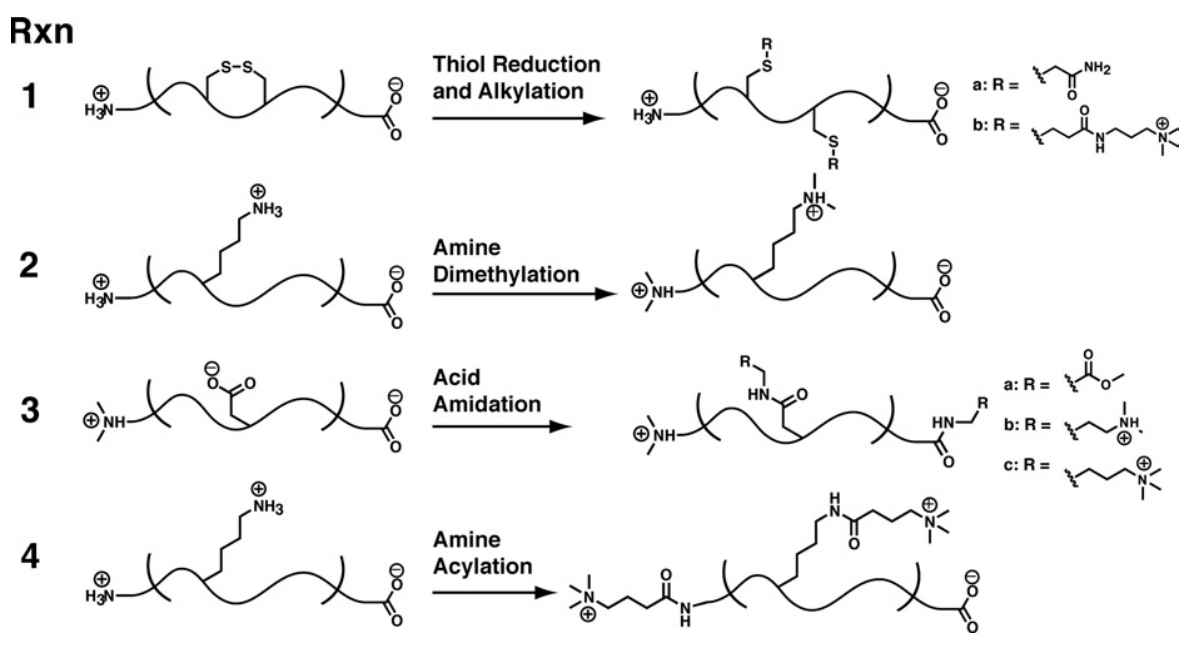

Figure 1. Chemical reactions used for the modification of whole proteins.

charging of ions by the production of radical cations has been demonstrated by electron impact or by collisions with molecular oxygen in the gas phase [40,41]. McLafferty and coworkers demonstrated the benefits of increased charging for improved fragmentation of a $29 \mathrm{kDa}$ protein [3]. Electron capture dissociation (ECD) of these high charge states provided cleavage of $97 \%$ of the inter-residue bonds, thereby yielding more protein sequence information. More recently Loo and coworkers achieved increased charging of noncovalent protein complexes with $m$-nitrobenzyl alcohol as a spray additive, which shows promise for facilitating study of native protein complexes [42].

Guided by the known contributions of functional groups to the charge state distribution (CSD), we employ chemical modifications to alter the CSD of denatured proteins in ESI-MS, including some examples that substantially increase protein charging. Proteins were fully modified by one or more of the reactions shown in Figure 1: thiol alkylation (Rxn 1), amine alkylation (Rxn $2)$, acid amidation ( $R \times n 3)$, and amine acylation ( $R \times n 4)$. Table 1 provides a summary of the various modified proteins used in the current work. The ESI-MS spectra of these proteins provide insight into the role of acidic and basic functional groups on charging in positive mode ESI. Further insights into how protein functional groups affect the charging of denatured proteins could contribute to developments in charge state manipulation and thereby facilitate protein characterization.

\section{Experimental}

\section{Materials}

All synthetic reagents were obtained from Aldrich (Milwaukee, WI) unless specified otherwise. (7-Azabenzotriazol-1yloxy)tripyrrolidinophosphonium hexafluorophosphate (PyAOP) was purchased from Applied Biosystems (Foster City, CA, USA). (4-Aminobutyl)trimethylammonium dichloride and [3-(2,6-difluorophenoxycarbonyl)propyl]trimethylammonium iodide were prepared as described previously [43]. The three standard proteins (bovine ubiquitin, bovine ribonuclease $\mathrm{A}$, and chicken lysozyme) were obtained from Sigma (St. Louis, MO, USA).

\section{Protein Derivatization}

Protein modifications were performed similarly to those described previously [43]. Briefly, thiol alkylation with iodoacetamide (Rxn 1a) was performed after thiol reduction in $60 \mathrm{mM} \mathrm{NH}_{4} \mathrm{HCO}_{3}$ buffer with $6 \mathrm{M}$ guanidine$\mathrm{HCl}$ and $40 \mathrm{mM}$ DTT at $5 \mathrm{mg} / \mathrm{mL}$ protein concentration at $37^{\circ} \mathrm{C}$ for $1 \mathrm{~h}$. Reactions were diluted to $2.5 \mathrm{mg} / \mathrm{mL}$ with buffer containing $50 \mathrm{mM}$ iodoacetamide and allowed to proceed at room-temperature in the dark for $1.5 \mathrm{~h}$. For alkylation with (3-acrylamidopropyl)trimethylammonium chloride (APTA) (Rxn 1b), the thiol reduction reactions were diluted with $4 \mathrm{M}$ APTA in $\mathrm{H}_{2} \mathrm{O}$ to $3.3 \mathrm{mg} / \mathrm{mL}$ protein concentration and allowed to react at room-temperature in the dark for $3 \mathrm{~h}$.

Amine reductive methylation ( $\mathrm{Rxn} 2$ ) was performed on proteins previously thiol-alkylated or proteins lacking thiols. Protein was dissolved in $300 \mathrm{mM}$ triethanolamine buffer at $\mathrm{pH} 7.5$ with $6 \mathrm{M}$ guanidine- $\mathrm{HCl}$ to 1.25 $\mathrm{mg} / \mathrm{mL}$ and then diluted with methanol to $1 \mathrm{mg} / \mathrm{mL}$. Pyridine- $\mathrm{BH}_{3}$ and formaldehyde were added to final concentrations of $30 \mathrm{mM}$ and $20 \mathrm{mM}$, respectively. Reactions were sonicated briefly and allowed to react at room-temperature for $2 \mathrm{~h}$.

Acid amidation ( Rxn 3 ) was performed on proteins that had been previously thiol-alkylated (if present) and amine methylated. Protein was dissolved in wet DMSO $\left(\sim 5 \% \mathrm{H}_{2} \mathrm{O}\right)$ to $1.5 \mathrm{mg} / \mathrm{mL}$. For glycine methyl ester modification (Rxn3a), glycine methyl ester $\mathrm{HCl}(1 \mathrm{M})$, n-methylmorpholine (NMM) (750 mM) and PyAOP (40 $\mathrm{mM}$ ) were added to the protein solutions. Reactions were allowed to proceed at room-temperature for $2 \mathrm{~h}$ 
Table 1. Listing of chemically modified proteins with number of modifications, calculated masses, and observed masses

\begin{tabular}{|c|c|c|c|c|c|}
\hline $\begin{array}{l}\text { Protein } \\
\text { (Modification Rxn \# from Fig. 1) }\end{array}$ & Thiol mods. & Amine mods. & Acid mods. & $\begin{array}{l}\text { Calc. avg. } \\
\text { mass (Da) }\end{array}$ & $\begin{array}{l}\text { Obs. avg. } \\
\text { mass (Da) }\end{array}$ \\
\hline $\begin{array}{l}\text { Ubiquitin } \\
\text { Dimethylated (2) }\end{array}$ & na & $\begin{array}{l}0 \\
8\end{array}$ & $\begin{array}{l}0 \\
0\end{array}$ & 8564.9 & $\begin{array}{l}8564.4 \\
8789.0\end{array}$ \\
\hline $\begin{array}{l}\text { Dimethylated (2) } \\
\text { GlyOMe amidated (3a) }\end{array}$ & na & 8 & 0 & 9590.4 & 9589.9 \\
\hline $\begin{array}{l}\text { Dimethylated (2) } \\
3^{\circ} \text {-amine amidated }(3 b)\end{array}$ & na & 8 & 12 & 9641.9 & 9641.7 \\
\hline $\begin{array}{l}\text { Dimethylated (2) } \\
\text { Fixed-charge amidated (3c) }\end{array}$ & na & 8 & 12 & 9798.9 & 9798.7 \\
\hline Fixed-charge acylated (4) & na & 8 & 12 & 10147.7 & 10147.2 \\
\hline $\begin{array}{l}\text { RNase A } \\
\quad \text { Thiol-alkylated (1a) }\end{array}$ & 8 & 0 & 0 & 14146.7 & 14146.4 \\
\hline $\begin{array}{l}\text { Thiol-alkylated (1a) } \\
\text { Dimethylated (2) } \\
\text { GlyOMe Amidated (3a) }\end{array}$ & 8 & 11 & 11 & 15236.7 & 15236.8 \\
\hline $\begin{array}{l}\text { Thiol-alkylated (1a) } \\
\text { Dimethylated (2) } \\
\text { Fixed-charge Amidated (3c) }\end{array}$ & 8 & 11 & 11 & 15700.4 & 15700.6 \\
\hline Fixed-charge thiol-alkylated (1b) & 8 & 0 & 0 & 15060.4 & 15061.0 \\
\hline $\begin{array}{l}\text { Lysozyme } \\
\text { Thiol-alkylated (1a) }\end{array}$ & 8 & 0 & 0 & 14769.6 & 14769.2 \\
\hline $\begin{array}{l}\text { Thiol-alkylated (1a) } \\
\text { Dimethylated (2) } \\
\text { GlyOMe amidated (3a) }\end{array}$ & 8 & 7 & 10 & 15676.5 & 15676.1 \\
\hline $\begin{array}{l}\text { Thiol-alkylated (1a) } \\
\text { Dimethylated (2) } \\
\text { Fixed-charge amidated (3c) }\end{array}$ & 8 & 7 & 10 & 16098.0 & 16098.0 \\
\hline Fixed-charge thiol-alkylated (1b) & 8 & 0 & 0 & 15683.3 & 15682.9 \\
\hline
\end{tabular}

and were then quenched with the addition of an equal volume of $\mathrm{H}_{2} \mathrm{O}$. Coupling with 3-(dimethylamino)-1propylamine (Rxn $3 b)$ and 4-(trimethylammonio) butylamine (Rxn 3c) used $500 \mathrm{mM}$ of the diamine diHCl salt with $350 \mathrm{mM}$ NMM. Also these reactions used 60 $\mathrm{mM}$ PyAOP and required an additional $10 \% \mathrm{H}_{2} \mathrm{O}$ to solubilize the amine salt.

Amine acylation (Rxn 4) was performed with the difluorophenol ester of 4-(trimethylamino)3-butyric acid, prepared as previously described [43]. Acylation was performed on ubiquitin $(0.5 \mathrm{mg})$ dissolved in 300 mM HEPES buffer $\mathrm{pH} 8.0$ with $6 \mathrm{M}$ guanidine- $\mathrm{HCl}(0.25$ $\mathrm{mL})$. The active ester $(9.6 \mathrm{mg}, 25 \mu \mathrm{mol})$ was added and allowed to react overnight at room-temperature. Protein was exchanged into $6 \mathrm{M}$ guanidine- $\mathrm{HCl}$ in $\mathrm{H}_{2} \mathrm{O}$ in a 5K MWCO Amicon Ultra centrifugal filter device (Millipore, Billerica, MA, USA). An equal volume of 200 $\mathrm{mM} \mathrm{LiOH}$ in $6 \mathrm{M}$ guanidine- $\mathrm{HCl} \mathrm{pH} 12.5$ was added to hydrolyze esters at $5{ }^{\circ} \mathrm{C}$ for $3 \mathrm{~h}$.

Proteins with multiple modifications were purified and desalted by HPLC between reaction steps to minimize adverse effects from previous reaction components. Proteins were purified by reverse-phase HPLC on a YMC C18 ODS-A $100 \times 10 \mathrm{~mm}$ column on a Beckman Coulter (Fullerton, CA, USA) System Gold HPLC.

\section{Mass Spectrometry}

The ESI-MS spectra in the figures were acquired with a Bruker micrOTOF mass spectrometer (Bruker Daltonics, Billerica, MA, USA). Many of the samples were also analyzed with two other ESI-MS instruments, and the resulting charge state distributions were quite similar. The protein samples dissolved in 1:1 $\mathrm{H}_{2} \mathrm{O}: \mathrm{MeOH}$ containing $0.2 \%$ formic acid were infused with a syringe pump at a flow rate of $4 \mu \mathrm{L} / \mathrm{min}$. The protein concentration was $2 \mu \mathrm{M}$ for ubiquitin samples and $0.5 \mu \mathrm{M}$ for ribonuclease A and lysozyme samples. All electrospray ionization was performed in positive mode by holding the stainless steel spray needle at ground and the capillary inlet at $-4500 \mathrm{~V}$. The nebulizer gas pressure was $0.3 \mathrm{bar}$, and the dry gas flow rate was $2 \mathrm{~L} / \mathrm{min}$ at $200{ }^{\circ} \mathrm{C}$. The potential difference between the capillary exit and the first skimmer was $100 \mathrm{~V}$. Spectra were recorded as the average obtained over $30 \mathrm{~s}$.

The signal intensities were not dramatically different for the various modified forms of each type of parent protein. Some variation was observed, but we attribute that mostly to differences in protein concentrations resulting from small losses during the course of sample handling through several steps of chemical modifica- 
(a)

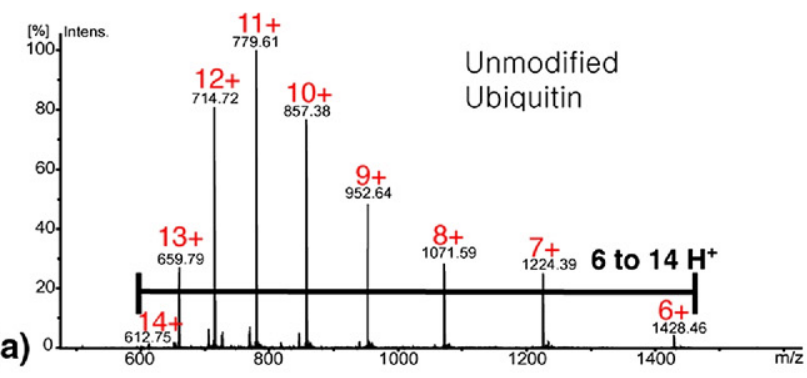

(c)

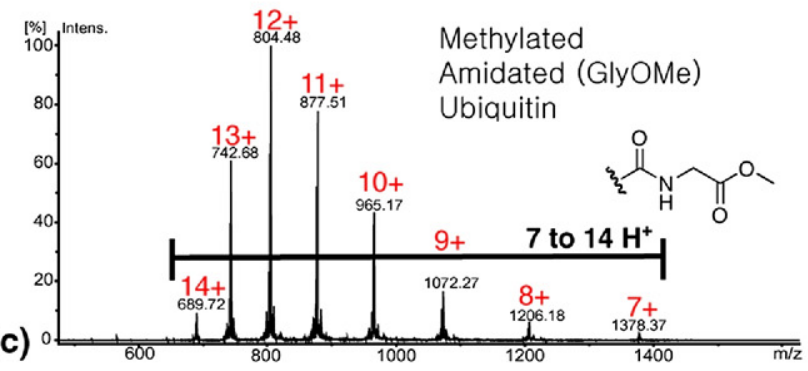

(e)

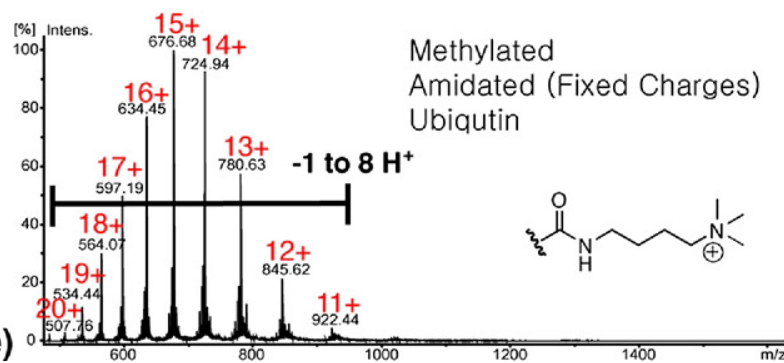

(b)

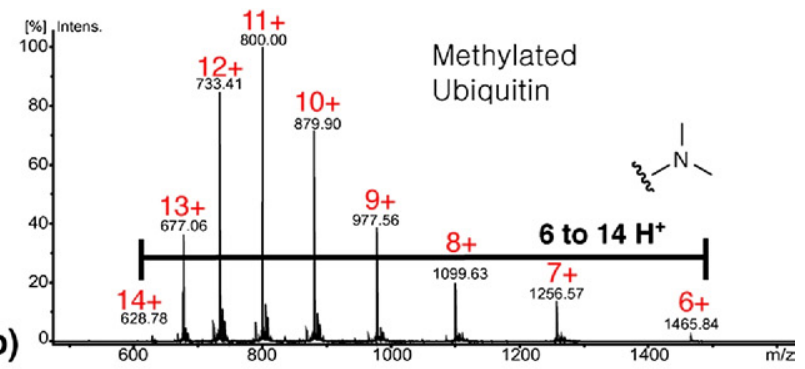

(d)

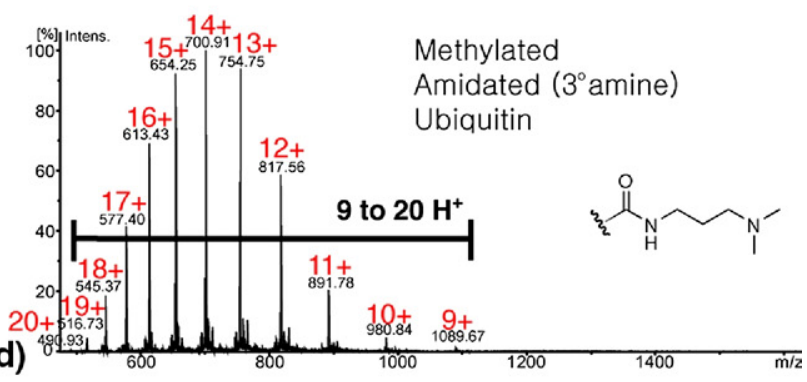

(f)

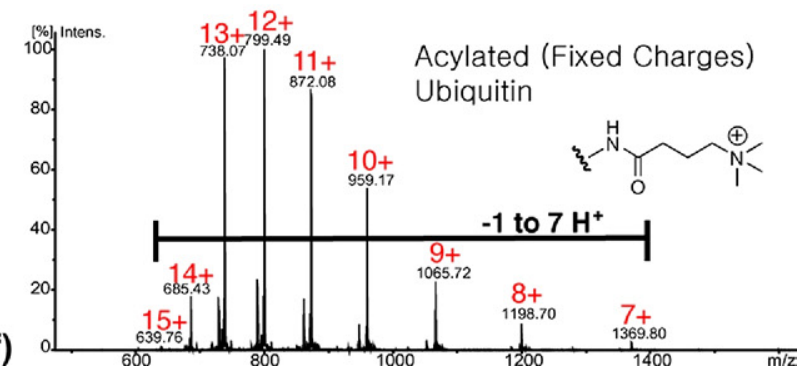

Figure 2. ESI-MS spectra showing the charge state distributions of unmodified ubiquitin (a) and various chemically-modified forms (b)-(f). The charge states are indicated in red. The ranges of net protons are given in black, determined by subtracting the number of fixed charges from the range of observed charge states (e.g., the protein in (f) has eight fixed charges, so the $7+$ to $15+$ ions have -1 to 7 net protons).

tion. Additional "noise" in some spectra is due to side products from the modification reactions and not from low signal intensity.

\section{Results}

We examined the charge state distributions of denatured proteins that were chemically modified at various functional groups. The modified proteins are summarized in Table 1, which indicates the modification reactions that were performed and the number of functional groups that were modified. Theoretical and observed masses for each protein were in excellent agreement $(\leq 0.6 \mathrm{Da})$, confirming that the derivatization reactions produced proteins with the expected modifications.

Figure 2 shows the ESI-MS spectra for the various modified forms of the protein ubiquitin. The spectrum of denatured, unmodified ubiquitin (Figure 2a) shows a charge state distribution (CSD) that ranges from +6 to +14 , which agrees with spectra shown in the literature $[2,44]$. Comparing Figure 2a and b, the CSD does not change upon methylation of the eight amino groups (seven lysines plus one $\mathrm{N}$-terminus). After methylating the native amino groups, the carboxylic acid groups
(Asp, Glu, and C-terminus) were amidated with various primary amines (Rxns 3a-c in Figure 1).

Amidation of the carboxylic acids with the methyl ester of glycine (GlyOMe) caps the acidic functional groups with a neutral, non-ionizable group, as shown in the inset of Figure 2c. This modification of ubiquitin leads to a slight change in the CSD, specifically an increase of a little less than one charge state (now +7 to +14 with +12 being the most intense). A similar small shift in charge state is observed for the same modification performed with two other proteins, ribonuclease $\mathrm{A}$ and lysozyme (compare spectrum $b$ with a in Figures 3 and 4). Note that unlike ubiquitin, these proteins contain disulfide linkages, and thus were first reduced and alkylated to obtain the fully denatured protein spectra used for comparison (Figures 3a and 4a). Capping all of the potentially negatively-charged acid groups for these three model proteins produces only a small change in their charge state distributions.

Conversion of the carboxylic acid groups into basic groups, by appending either a tertiary or quaternary amine, leads to a significant increase in charging during ESI-MS. The amidation of 12 acid groups in ubiquitin with tertiary amines produces a range of charge states 
(a)

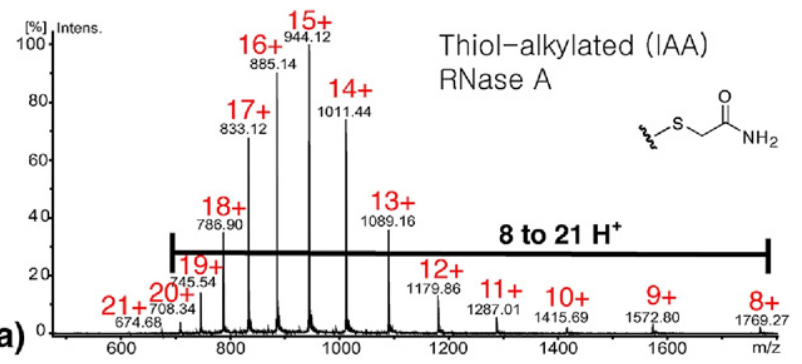

(b)

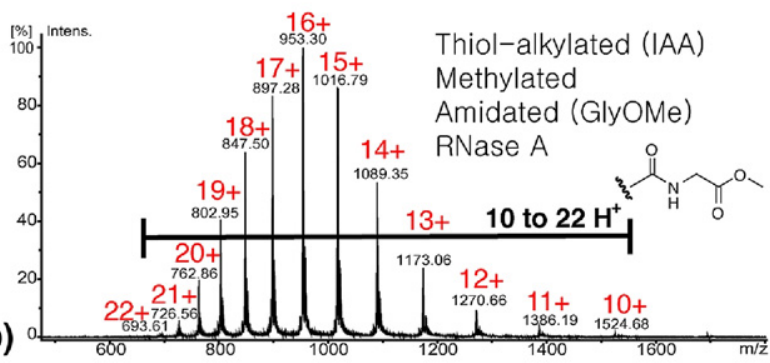

(c)

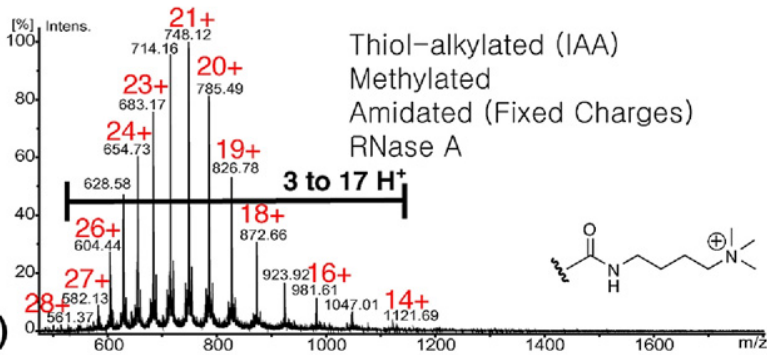

(d)

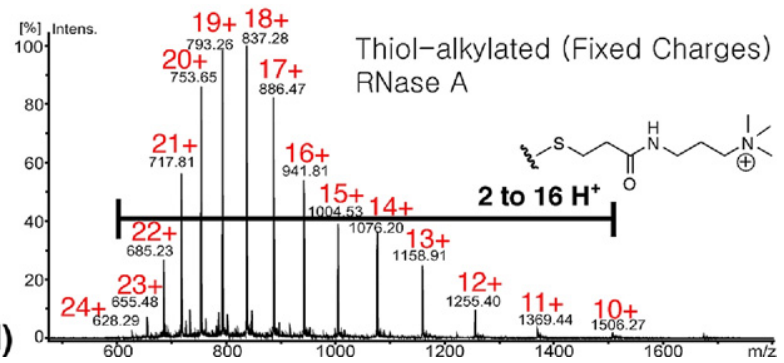

Figure 3. ESI-MS spectra showing the charge state distributions of modified ribonuclease A (RNase A) proteins. Spectrum (a) is for the reduced and alkylated version of the protein and serves as a control spectrum for comparison with the spectra for the other modifications.

from +9 to +20 (Figure $2 \mathrm{~d}$ ), substantially higher than the +6 to +14 for the unmodified protein. Amidation with fixed-charge quaternary ammonium groups shifts the charge state distribution even more to yield a range of +11 to +20 with +15 now being the most intense peak (Figure 2e). It is noteworthy that appending 12 fixed charges to this protein did not increase the charge states in the distribution by 12 , which would have produced a range of +18 to +26 . Thus, the fixed-charge modified protein is acquiring fewer protons during electrospray ionization, as indicated in Figure $2 \mathrm{e}$ by the designation of -1 to $8 \mathrm{H}^{+}$(calculated by subtracting the 12 fixed charges from the observed CSD of +11 to +20 ). Intriguingly, the presence of the +11 charge state on this protein with 12 fixed charges indicates the presence of at least one negative charge for this ion. The RNase A and lysozyme proteins also showed significant increases in charging when fixed charges were added at acidic sites (Figures $3 \mathrm{c}$ and $4 \mathrm{c}$ ), and again the CSD did not shift by the full number of fixed charges.

Fixed charge groups were attached to these model proteins at other functional groups besides the carboxylic acids. Ubiquitin was acylated at its native amino groups to append eight fixed charges and eliminate the eight primary amino groups. Replacing these protonatable basic groups with fixed positive charges produces a modest increase in charging, whereby the range becomes +7 to +15 (Figure $2 \mathrm{f}$ ) compared with the +6 to +14 for the control spectrum (Figure 2a). As addressed in the Discussion section, we had anticipated a narrowing of the CSD, but that result did not occur. The thiol

(a)

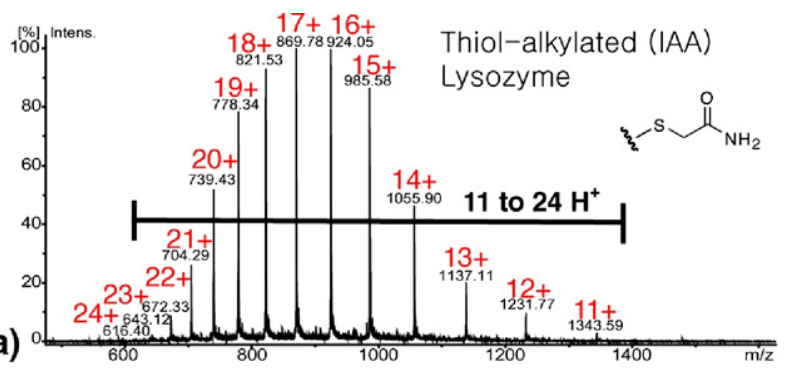

(b)
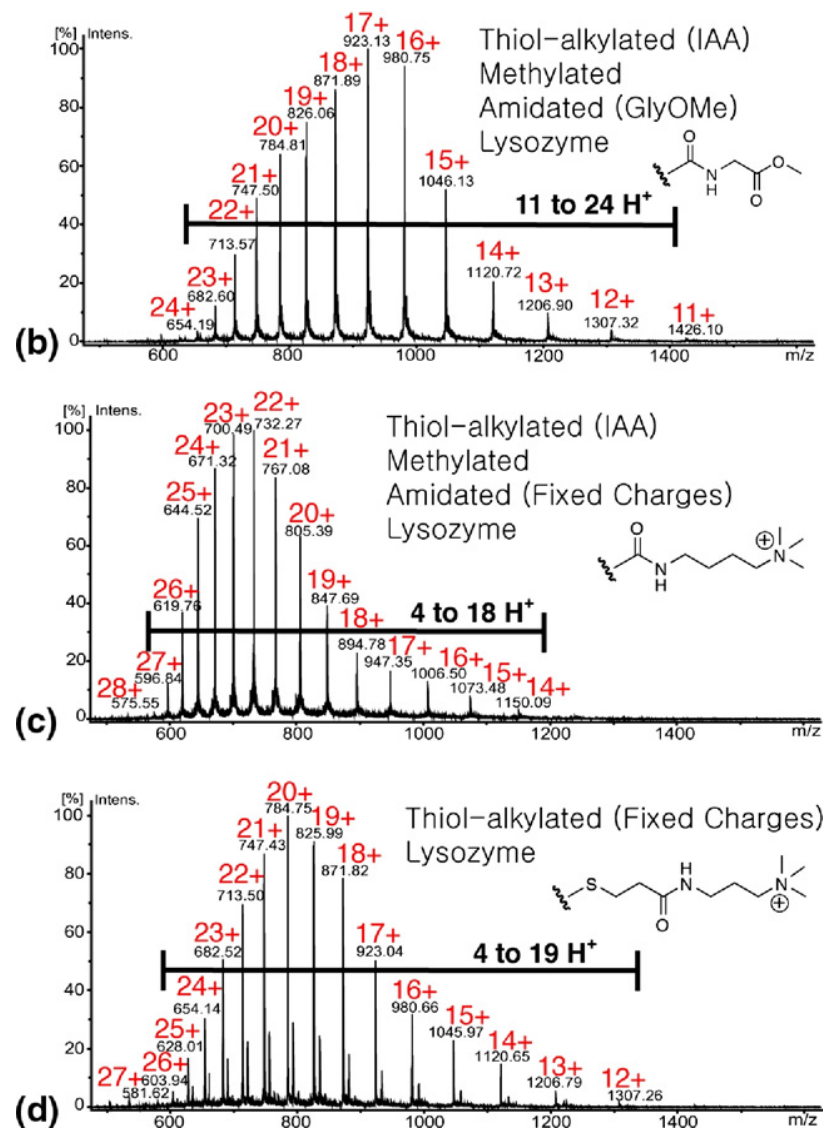

Figure 4. ESI-MS spectra showing the charge state distributions of modified lysozyme proteins. As in Figure 3, spectrum (a) is the reduced and alkylated protein spectrum for comparison. 
sites in RNase A and lysozyme served as another point of attachment for fixed charges by alkylating them with the APTA reagent, as performed previously on peptides [45]. Appending fixed positive charges to the thiol sites and not interfering with any of the ionizable groups on the proteins led to an increase in charging (compare spectrum d to a in Figures 3 and 4). Once again the shift in CSD is much less than eight charges, the number of fixed charges added in these two cases.

\section{Discussion}

As outlined in the introduction, the literature contains some evidence for the involvement of carboxyl groups in positive mode ESI-MS of peptides and folded proteins. To explore this possibility for denatured proteins, we chose to modify proteins such that the carboxylic acid groups were capped by amidation with neutral groups (Rxn 3a). If the carboxyls were playing a role in determining CSD either through salt-bridging or hydrogen bonding with basic sites, then the removal of all acidic sites on the protein would likely increase the overall charging leading to higher charge states in the ESI spectrum. Only a small shift of $\leq 1$ charge state was observed between the CSDs for the "acid-capped" and the unmodified forms of the three modified proteins (compare spectra: $2 c$ with $2 a, 3 b$ with $3 a$, and $4 b$ with $4 a$ ). This result indicates that the presence of acidic residues plays only a minor role in the charging of denatured proteins during positive-mode ESI-MS. Also, it demonstrates that capping acidic groups with neutral moieties is not a successful approach for modifying the CSD of proteins.

This minor role of carboxyl groups in determining the CSD could occur through stabilization of partiallyfolded structures that contain salt-bridges or hydrogenbonds. The observed result of only a small change in CSD upon carboxyl amidation does not rule out the presence of negatively charged residues in unmodified proteins in the gas-phase. The capping of the acidic residues may effectively replace doubly cationic salt bridge motifs, $(+) \ldots(-) \ldots(+)$, with singly-protonated cationic sites, which yields the same net charge for the ions. The small change in CSD also implies that carboxyls do not contribute dramatically to stabilizing partially folded structures, which was a possible explanation for the abundance of ions in "less-than-maximum" charge states of denatured proteins during positivemode ESI.

On the other hand, we did observe significant changes in protein charge state distributions upon addition of tertiary or quaternary amines at either acid or thiol functional groups (Figures $2 \mathrm{~d}$ and e, 3c and d, 4c and $d$ ). These spectra show a marked shift to higher charge states for each of the three proteins. Amidating methylated ubiquitin with fixed charges shifts the CSD from 6-14 charges (Figure 2a) to 11-20 charges (Figure 2e). A similar change was observed from the addition of tertiary amines (Figure 2d) with a shift to 9-20 charges. Addition of fixed charges to RNaseA and lysozyme by acid amidation or by thiol alkylation also gave a similar shift of the CSD. These modifications are potentially useful for facilitating MS approaches that benefit from more highly charged (lower $m / z$ ) ions (e.g., ECD, ETD, and FT-MS of intact proteins) [3, 46, 47].

The increased charging observed upon adding fixed charges or additional basic groups indicates that the number of basic functional groups on unmodified, denatured proteins generally limits the extent of their charging. Increased charging for these modified proteins may have been expected in light of Williams's charging model for denatured proteins, which states that charging is largely governed by gas-phase basicity of ionizable sites. Interestingly, this result differs from some recent reports on the charging of folded proteins, which indicate charge state is largely determined by molecular shape, as measured by solvent-exposed surface area in solution or gas-phase ion mobility diameter [21, 25]. According to these models, folded proteins have a sufficient number of exposed basic sites to accommodate the charge allowed for an ion of a particular size. So for folded proteins, the overall gas-phase basicity appears to be limited by size and not by the number of ionizable sites. In the present work with denatured proteins, the charge states increase significantly upon modification with fixed charges or additional basic groups with only a small increase in molecular size. Thus, our results provide evidence that for denatured proteins, the extent of charging is determined predominantly by the number of ionizable sites.

This result may have implications for employing ESI spectra to assess the geometry of partially folded proteins in solution. While ESI charge state distributions can reflect the physical dimensions of folded proteins, the limiting number of basic groups may not allow such inferences to be made with partially denatured species. Additionally, this paucity of ionizable sites suggests that appending fixed charges or additional basic groups to a denatured protein past a critical point could enable the CSD to then be governed by molecular size and not by gas-phase basicity. This may result in CSDs with only a few charge states, mimicking behavior typically observed with folded proteins. Attempts to test this hypothesis by modifying proteins with additional quaternary amines have proven unsuccessful so far due to difficulties in chemical modification (e.g., acid amidation was attempted with a compound bearing two quaternary amine groups).

The ESI-MS analysis of the fixed-charge modified proteins clearly illustrates that Coulombic repulsion between positive charges does significantly affect gasphase basicity and the resulting charge state distributions. The addition of twelve fixed charges at the acidic groups of ubiquitin shifted the CSD to higher charge states (Figure 2e), but it did not simply shift it by the number of added charges. The fixed-charge modifications reduced the net number of protons acquired from a range of $6-14$ ( +6 to +14 charge states) to a range of -1 to 8 ( +11 to +20 charge states). The same trend in reducing the net protonation upon addition of fixed 
charges was observed for ribonuclease A and lysozyme (Figures $3 c$ and $d, 4 c$ and $d$ ). Through charge-charge repulsion, the addition of fixed charges at non-basic sites (carboxyls or thiols) significantly reduces the effective basicity of the basic sites on the protein. (Note that the basic sites themselves were sometimes minimally modified by dimethylation, but that change by itself had a negligible effect on CSD; see Figure 2b). This result illustrates that Coulombic repulsion is a key factor in determining charge state and its variability for denatured proteins. The location of basic residues (Arg, Lys, His), carboxyls, and thiols are generally well distributed throughout the sequences of these model proteins. Thus, these Coulombic repulsion effects have not been exaggerated by close clustering of the fixed charge modifications and the protein basic groups. These data also suggest an approach for concentrating the signal into a few high charge states, namely appending numerous fixed charges. While we have attached several fixed charges to these proteins, it has not been sufficient to completely prevent protonation of basic groups. Adding enough fixed charges on a protein would presumably further reduce the propensity for the protein to acquire protons, which could lead to a single charge state equal to the number of fixed charges (or a few charge states near this value). However, these effects may be counteracted by formation of salt-bridges, as discussed below.

The role of variable amine protonation in determining charge state distribution was also explored using amine acylation. Given our results with increasing charging along with Williams's charging model, we hypothesized that converting primary amine groups to fixed-charge quaternary amine groups (Rxn 4, Figure 1) might move the charge state distribution to higher states, and possibly narrow it as well. This hypothesis relies on the fact that primary amine groups (Lys, $\mathrm{N}$-terminus) are the most numerous basic groups in ubiquitin and are less basic than Arg residues (GB = $237 \mathrm{kcal} / \mathrm{mol}$ for Lys; $251 \mathrm{kcal} / \mathrm{mol}$ for Arg) [12]. Consequently, they are more likely to be deprotonated some of time, and as a result they might be the functional groups contributing most of the variability that leads to a distribution of charge states. The fixed charge acylation of ubiquitin increased the CSD slightly to a range of +7 to +15 charge states (compare Figure $2 \mathrm{f}$ with $2 \mathrm{a}$ ), while reducing the number of protons acquired to a range of -1 to 7. A significant narrowing of the CSD did not occur. Nonetheless, the observed shift to higher charge states for this fixed-charge acylated protein suggests that variable protonation at amine sites does play a role in the charge state distribution of denatured proteins.

The presence of the +7 charge state on the acylated protein with eight fixed charges (Figure 2f) indicates the presence of at least one negatively-charged group. In this case where negative charge(s) are present, they definitely affect the CSD, in that protein ions exist in lower charge states compared to what would occur without the negative charge(s). Possibly several negatively-charged groups are masking what would otherwise be a nar- rower CSD for this case where primary amines (with their possibility of being charged or not charged) have been converted to fixed-charge quaternary amines. The negative charge(s) on this acylated protein are most likely deprotonated carboxyls because they would have the lowest gas-phase basicity of the possible negativelycharged groups $(\mathrm{GB}=335 \mathrm{kcal} / \mathrm{mol})$ [11]. It is also probable that these carboxylate groups are stabilized by formation of a salt bridge with one or more of the fixed positive charges. Attempts to prevent carboxylate formation by capping the acid groups with neutral groups (e.g., glycine methyl ester) on this acylated protein were unsuccessful. Another example of a negatively-charged group occurs for the fixed-charge amidated ubiquitin (Figure 2e), and this modified protein did not contain any carboxyl groups. While less favorable than carboxylate formation, deprotonation of phenols or the amide backbone itself may also occur (GB = $342 \mathrm{kcal} / \mathrm{mol}$ for phenoxide, GB = $355 \mathrm{kcal} / \mathrm{mol}$ for deprotonated methyl acetamide) [11]. Deprotonation at these sites would become increasingly energetically favorable on a highly positively-charged ion. It is worth noting that fixed-charge modified proteins are more likely to form salt-bridge motifs, since fixed-charge positive ions cannot transfer a proton to neutralize a negatively-charged group. Thus, the formation of salt bridges may limit the extent of increased charging that can be obtained by appending fixed charges to proteins.

\section{Conclusions}

Several chemical modifications were employed to investigate the roles of protein functional groups in determining charge state distributions in denatured, positive-mode ESI spectra. The minimal change in the CSD with amidation of protein acids with neutral groups indicates that the presence of carboxyl groups has little bearing on CSDs. Modification of proteins with additional basic sites or fixed charges indicates that charging of denatured proteins is often limited by the number of ionizable sites. This result suggests that the number of ionizable sites and their gas-phase basicities are major factors in determining CSDs of unfolded proteins. These chemical modifications offer a useful strategy for increasing the charging of proteins to facilitate MS characterization. The chemical labeling of proteins with fixed charges produced a greater increase in charging than that obtained by previously published approaches for increasing charging in ESI. While chemical modification can be laborious, the near quantitative transformations achieved with these reactions make this a viable approach for studying proteins in certain applications. Further development in chemical derivatization conditions may enable more extensive addition of fixed charges or basic groups to proteins, which may lead to narrow distributions of very high charge states for ESI-MS of denatured proteins. Combining these modifications with ion/molecule and ion/ion reactions in the gas-phase 
has already illustrated some unique approaches for altering protein charge state distributions [48].

\section{Acknowledgments}

The authors thank Martha Vestling, Jonathan Ferguson, Neil Kelleher, and Pehr Harbury for insightful discussions. C.J.K. was supported by the NIH Biotechnology Training Grant Fellowship. The authors acknowledge support for this work by the National Heart Lung Blood Institute (NHLBI) Proteomics Program N01HV-28,182, and also by NIH grants R01GM065406 to P.J.B. and R33DK070297 to L.M.S.

\section{References}

1. Stephenson, J. L.; McLuckey, S. A. Gaseous Protein Cations are Amphoteric. J. Am. Chem. Soc. 1997, 119, 1688-1696.

2. Smith, R. D.; Loo, J. A.; Ogorzalek Loo, R. R.; Busman, M.; Udseth, H. R. Principles and Practice of Electrospray Ionization-Mass Spectrometry for Large Polypeptides and Proteins. Mass Spectrom. Rev. 1991, 10, 359-452.

3. Sze, S. K.; Ge, Y.; Oh, H.; McLafferty, F. W. Top-Down Mass Spectrometry of a 29-kDa Protein for Characterization of Any Post-Translational Modification to Within One Residue. Proc. Nat. Acad. Sci. U.S.A. 2002, 99, 1774-1779.

4. Reid, G. E.; Wu, J.; Chrisman, P. A.; Wells, J. M.; McLuckey, S. A. Charge-State-Dependent Sequence Analysis of Protonated Ubiquitin Ions Via Ion Trap Tandem Mass Spectrometry. Anal. Chem. 2001, 73, 3274-3281.

5. Kelleher, N. L. Top-Down Proteomics. Anal. Chem. 2004, 76, 196A-203A.

6. Iavarone, A. T.; Williams, E. R. Mechanism of Charging and Supercharging Molecules in Electrospray Ionization. J. Am. Chem. Soc. 2003, 125, 2319-2327.

7. Wang, G.; Cole, R. B. Solution, Gas-Phase, and Instrumental Parameter Influences on Charge-State Distributions in Electrospray Ionization Mass Spectrometry. In Electrospray Ionization Mass Spectrometry; Cole, R. B., Ed. Wiley: New York, 1997; pp 137-174.

8. Kjeldsen, F.; Silivra, O. A.; Zubarev, R. A. Zwitterionic States in Gas-Phase Polypeptide Ions Revealed by 157-nm Ultraviolet Photodissociation. Chem. Eur. J. 2006, 12, 7920-7928.

9. Downard, K. M.; Biemann, K. Charging Behavior of Highly Basic Peptides During Electrospray-Ionization-A Predilection for Protons. Int. J. Mass Spectrom. Ion Processes 1995, 148, 191-202.

10. Samalikova, M.; Grandori, R. Role of Opposite Charges in Protein Electrospray Ionization Mass Spectrometry. J. Mass Spectrom. 2003, 38, 941-947.

11. Hunter, E. P.; Lias, S. G. NIST Chemistry Web book. In NIST Standard Reference Database Number 69 [Online] Mallard, W. G.; Lindstrom, P. J., Ed. National Institute of Standards and Technology: Gaithersburg, MD, 2005. http://webbook.nist.gov/chemistry.

12. Peschke, M.; Blades, A.; Kebarle, P. Charged States of Proteins. Reactions of Doubly Protonated Alkyldiamines with $\mathrm{NH}(3)$ : Solvation or Deprotonation. Extension of Two Proton Cases to Multiply Protonated Globular Proteins Observed in the Gas Phase. J. Am. Chem. Soc. 2002, 124, 11519-11530.

13. Schnier, P. D.; Gross, D. S.; Williams, E. R. On the Maximum ChargeState and Proton-Transfer Reactivity of Peptide and Protein Ions Formed by Electrospray-Ionization. J. Am. Soc. Mass Spectrom. 1995, 6, 1086-1097.

14. Touboul, D.; Jecklin, M. C.; Zenobi, R. Investigation of Deprotonation Reactions on Globular and Denatured Proteins at Atmospheric Pressure by ESSI-MS. J. Am. Soc. Mass Spectrom. 2008, 19, 455-466.

15. Schnier, P. D.; Price, W. D.; Williams, E. R. Modeling the Maximum Charge State of Arginine-Containing Peptide Ions Formed by Electrospray Ionization. J. Am. Soc. Mass Spectrom. 1996, 7, 972-976.

16. Price, W. D.; Jockusch, R. A.; Williams, E. R. Is Aarginine a Zwitterion in the Gas Phase? J. Am. Chem. Soc. 1997, 119, 11988-11989.

17. Strittmatter, E. F.; Williams, E. R. Structures of Protonated Arginine Dimer and Bradykinin Investigated by Density Functional Theory: Further Support for Stable Gas-Phase Salt Bridges. J. Phys. Chem. A 2000, 104, 6069-6076

18. Grandori, R. Origin of the Conformation Dependence of Protein Charge-State Distributions in Electrospray Ionization Mass Spectrometry. J. Mass Spectrom. 2003, 38, 11-15.

19. Prakash, H.; Mazumdar, S. Direct Correlation of the Crystal Structure of Proteins with the Maximum Positive and Negative Charge States of Gaseous Protein Ions Produced by Electrospray Ionization. J. Am. Soc. Mass Spectrom. 2005, 16, 1409-1421.

20. Verkerk, U. H.; Kebarle, P. Ion-Ion and Ion-Molecule Reactions at the Surface of Proteins Produced by Nanospray. Information on the Number of Acidic Residues and Control of the Number of Ionized Acidic and Basic Residues. J. Am. Soc. Mass Spectrom. 2005, 16, 1325-1341.

21. Kaltashov, I. A.; Mohimen, A. Estimates of Protein Surface Areas in Solution by Electrospray Ionization Mass Spectrometry. Anal. Chem. 2005, 77, 5370-5379.
22. Peschke, M.; Verkerk, U. H.; Kebarle, P. Prediction of the Charge States of Folded Proteins in Electrospray Ionization. Eur. J. Mass Spectrom. 2004, 10, 993-1002.

23. Nesatyy, V. J.; Suter, M. J. F. On the Conformation-Dependent Neutralization Theory and Charging of Individual Proteins and Their Noncovalent Complexes in the Gas Phase. J. Mass Spectrom. 2004, 39, 93-97.

24. Hogan, C. J.; Carroll, J. A.; Rohrs, H. W.; Biswas, P.; Gross, M. L. Combined Charged Residue-Field Emission Model of Macromolecular Electrospray Ionization. Anal. Chem. 2009, 81, 369-377.

25. Hogan, C. J.; Carroll, J. A.; Rohrs, H. W.; Biswas, P.; Gross, M. L. Charge Carrier Field Emission Determines the Number of Charges on Native State Proteins in Electrospray Ionization. J. Am. Chem. Soc. 2008, 130, 6926-6927.

26. Fernandez de la Mora, J. Electrospray Ionization of Large Multiply Charged Species Proceeds Via Dole's Charged Residue Mechanism. Anal. Chim. Acta 2000, 406, 93-104.

27. Felitsyn, N.; Peschke, M.; Kebarle, P. Origin and Number of Charges Observed on Multiply-Protonated Native Proteins Produced by ESI. Int. J. Mass Spectrom. 2002, 219, 39-62.

28. Carbeck, J. D.; Severs, J. C.; Gao, J.; Wu, Q.; Smith, R. D.; Whitesides, G. M. Correlation between the Charge of Proteins in Solution and in the Gas Phase Investigated by Protein Charge Ladders, Capillary Electrophoresis, and Electrospray Ionization Mass Spectrometry. J. Phys. Chem. B 1998, 102, 10596-10601.

29. Clemmer, D. E.; Hudgins, R. R.; Jarrold, M. F. Naked Protein ConformationsCytochrome $c$ in the Gas Phase. J. Am. Chem. Soc. 1995, 117, 10141-10142.

30. Horn, D. M.; Breuker, K.; Frank, A. J.; McLafferty, F. W. Kinetic Intermediates in the Folding of Gaseous Protein Ions Characterized by Electron Capture Dissociation Mass Spectrometry. J. Am. Chem. Soc. 2001, 123, 9792-9799.

31. Koeniger, S. L.; Merenbloom, S. I.; Clemmer, D. E. Evidence for Many Resolvable Structures Within Conformation Types of Electrosprayed Ubiquitin ions. J. Phys. Chem. B 2006, 110, 7017-7021.

32. Lemaire, D.; Marie, G.; Serani, L.; Laprevote, O. Stabilization of GasPhase Noncovalent Macromolecular Complexes in Electrospray Mass Spectrometry Using Aqueous Triethylammonium Bicarbonate Buffer. Anal. Chem. 2001, 73, 1699-1706.

33. Verkerk, U. H.; Peschke, M.; Kebarle, P. Effect of Buffer Cations and of $\mathrm{H} 3 \mathrm{O}+$ on the Charge States of Native Proteins. Significance to Determinations of Stability Constants of Protein Complexes. J. Mass Spectrom. 2003, 38, 618-631.

34. Catalina, M. I.; van den Heuvel, R. H.; van Duijn, E.; Heck, A. J. Decharging of Globular Proteins and Protein Complexes in Electrospray. Chem. Eur. J. 2005, 11, 960-968.

35. Mcluckey, S. A.; Vanberkel, G. J.; Glish, G. L. Reactions of Dimethylamine with Multiply Charged Ions of Cytochrome c. J. Am. Chem. Soc. 1990, 112, 5668-5670

36. Ikonomou, M. G.; Kebarle, P. An Ion-Source With Which Ions Produced by Electrospray Can be Subjected to Ion Molecule Reactions at Intermediate Pressures (10-100 Torr)-Deprotonation of Polyprotonated Peptides. Int. J. Mass Spectrom. Ion Processes 1992, 117, 283-298.

37. Scalf, M.; Westphall, M. S.; Krause, J.; Kaufman, S. L.; Smith, L. M. Controlling Charge States of Large Ions. Science 1999, 283, 194-197.

38. Pitteri, S. J.; McLuckey, S. A. Recent Developments in the Ion/Ion Chemistry of High-Mass Multiply Charged Ions. Mass Spectrom. Rev. 2005, 24, 931-958.

39. Iavarone, A. T.; Jurchen, J. C.; Williams, E. R. Supercharged Protein and Peptide Ions Formed by Electrospray Ionization. Anal. Chem. 2001, 73, 1455-1460.

40. Budnik, B. A.; Zubarev, R. A. $\mathrm{MH} 2+$. Ion Production from Protonated Polypeptides by Electron Impact: Observation and Determination of Ionization Energies and a Cross-Section. Chem. Phys. Lett. 2000, 316, 19-23.

41. Hvelplund, P.; Nielsen, S. B. N.; Sorensen, M.; Andersen, J. U.; Jorgensen, T. J. D. Electron Loss from Multiply Protonated Lysozyme Ions in High Energy Collisions with Molecular Oxygen. J. Am. Soc. Mass Spectrom. 2001, 12, 889-893.

42. Lomeli, S. H.; Yin, S.; Ogorzalek Loo, R. R.; Loo, J. A. Increasing Charge While Preserving Noncovalent Protein Complexes for ESI-MS. J. Am Soc. Mass Spectrom. 2009, 20, 593-596.

43. Krusemark, C. J.; Ferguson, J. T.; Wenger, C. D.; Kelleher, N. L. Belshaw, P. J. Global Amine and Acid Functional Group Modification of Proteins. Anal. Chem. 2008, 80, 713-720.

44. Katta, V.; Chait, B. T. Conformational Changes in Proteins Probed by Hydrogen-Exchange Electrospray-Ionization Mass Spectrometry. Rapid Commun. Mass Spectrom. 1991, 5, 214-217.

45. Ren, D.; Julka, S.; Inerowicz, H. D.; Regnier, F. E. Enrichment of Cysteine-Containing Peptides from Tryptic Digests Using a Quaternary Amine Tag. Anal. Chem. 2004, 76, 4522-4530.

46. Good, D. M.; Wirtala, M.; McAlister, G. C.; Coon, J. J. Performance Characteristics of Electron Transfer Dissociation Mass Spectrometry. Mol. Cell Proteom. 2007, 6, 1942-1951.

47. Bogdanov, B.; Smith, R. D. Proteomics by FTICR Mass Spectrometry: Top Down and Bottom Up. Mass Spectrom. Rev. 2005, 24, 168-200.

48. Frey, B. L.; Krusemark, C. J.; Ledvina, A. R.; Coon, J. J.; Belshaw, P. J.; Smith, L. M. Ion-Ion Reactions with Fixed-Charge Modified Proteins to Produce Ions in a Single, Very High Charge State. Int. J. Mass Spectrom. 2008, 276, 136-143. 